\title{
Development of a Portable Organic Vapour Analyser Using Quartz Crystal Piezoelectric Sorption Detector for Monitoring of Total Organic Compounds in Air
}

\author{
Y.S. Fung and Y. Y. Wong \\ Department of Chemistry, The University of Hong Kong, Pokfulam Road, Hong Kong
}

To solve the problem of high humidity interfering with the monitoring of organic vapours commonly found in workplace air using the piezoelectric crystal detector, a battery operated fan dryer was incorporated with the $P / Z$ detector to provide a light, sensitive and portable monitor for analysing organic vapours in air. The organic vapour monitor developed is sensitive to analyse organic vapours at ppm levels below the control limits of these vapours. To select a suitable coating for the P/Z crystal detector to be used for diumal monitoring of organic compounds in indoor air and in factories, eight gasliquid chromatography coatings was chosen for study. Based on their sensitivity, selectivity, bleeding rate and long term stability towards commonly encountered organic vapours such as 1,1,1trichloroethane, chloroform, benzene and toluene, Apeizon grease $\mathrm{L}$ was selected as the coating of the $\mathrm{P} / \mathrm{Z}$ crystal. The optimised analytical parameters are : temperature $22^{\circ} \mathrm{C}-43^{\circ} \mathrm{C}$, relative humidity $40 \%$ $100 \%$, response time $2-30$ minutes and linear working ranges $88.8 \mathrm{ppm}-1880 \mathrm{ppm}$.

Keywords : portable organic vapour monitor, piezoelectric crystal detector, moisture interference

Increasing concem has been shown recently on the level of volatile organic compounds in workplace air due to the toxicity of aromatic and halogenated solvent used in the manufacturing industry ${ }^{1}$.Thus, there is a need to determine volatile organic compounds in air at ppm range, as the TLV for these compounds are all in the ppm levels. However, in the industrial environment, it is quite often not practical to install analytical equipment requiring a weil controlled environment such as portable GC equipped with a photoionization detector. ${ }^{2}$. Thus, a light, portable and sensitive monitor is needed to assess situation of spillage of organic solvent, or to protect the workers working in an enclosed environment.

The recent advance in the piezoelectric quartz crystal (P/Z crystal) sorption detector provides a suitable method ${ }^{3-5}$ for such analysis due to its light weight, high sensitivity and low cost. The operation of the detector is based on the principle that the frequency of vibration of the oscillating crystal is decreased by the absorption of a foreign material on its surface. Sauerbrey had developed the relationship between the weight of the coating on the crystal and the change in frequency ${ }^{6}$ as given in the following equation :

$$
\Delta F=\frac{-\left(2.3 \times 10^{6}\right) F^{2} \Delta m}{A}
$$

where $\Delta F$ is the change in frequency due to the addition of the coating $(\mathrm{Hz}), \mathrm{F}$ is the fundamental frequency of the crystal $(\mathrm{MHz}), \Delta \mathrm{m}$ is the mass of coating adsorbed ( $(\mathrm{g})$, and $\mathrm{A}$ is the area coated $\left(\mathrm{cm}^{2}\right)$. Using a suitable coating material, the concentration of the gas can be determined quantitatively at $\mathrm{ppb}$ to ppm lovels.

The major problem facing the application of the P/Z crystal detector for environmental monitoring of organic vapours is the interference of moisture, that can be as high as more than $1000,000 \mathrm{ppm}$ in a highly humid day. As the concentration of most organic vapours with health concern are a few ppm in 
air, the selectivity is not good enough in most cases to avoid the interference of moisture during field measurement.

The recent development of a battery operated dryer in our laboratory ${ }^{7}$ modified from a domestic humidity controller using a $1.5 \mathrm{~V}$ compact DC motor to move air over a drying agent provides a suitable method to reduce the moisture interference problem as the relative humidity of the air sampled was shown to be reduced below $40 \%$ even the air intake is near saturation after one month continuous operation ?. The present work is the incorporation of this dryer with a P/Z crystal sorption detector and investigate the applicability of organic vapour monitor developed for monitoring organic solvents commonly used in industrial settings.

\section{Experimental section}

\section{Apparatus}

The construction of the organic vapour monitor is shown in Fig. 1. The total volume of the monitor is $1.8 \mathrm{~L}(15 \mathrm{~cm} \times 15 \mathrm{~cm} \times 8 \mathrm{~cm})$ and the total weight is about $500 \mathrm{~g}$. Air is drawn by the battery fan dryer (MR.DRY ${ }^{\mathbb{R}}$ Fan-A, ST Chemicals Corporation, Tokyo, Japan), blown over the dehydrated agent Anhydrous Calcium Chloride and then split into two equal streams, each passing through a $3 \mathrm{~mm}$ diameter hole. The two streams falls directly on the opposite faces of the crystal in the detector cell. The P/Z crystals used were commercially available AT-cut $10.000 \mathrm{MHz}$ quartz crystals with about $1.2 \mathrm{~cm}$ diameter, $0.5 \mathrm{~mm}$ thickness and silver-plated electrodes on both faces (C\&Y Trading Co., Ltd., Hong Kong). The instrumentation consisted of a frequency oscillator, $6 \mathrm{~V}$ dc regulated power supply and a frequency counter (Heathkit IM 4120 model) with accuracy of $\pm 1 \mathrm{~Hz}$. The face velocity of the air at the exit of unit was measured by a Thermo Anemometer (SIBATA, Model ISA - 20N).

\section{Reagents}

The coating materials used consisted of eight g.l.c. coatings : Squalane and Silicone 550 (E. Merck Darmstadt, Germany); DC High Vacuum Grease (HVG) (Dow Corning Corp. Midland, MI); Apeizon Grease L (AG) (GEC Alsthom Ltd., Manchester
England); Poly(ethylene glycol) 400 and 1000 (PEG 400 \& PEG 1000) (Aldrich); Carbowax 20M (Aldrich); Dioctyl phthalate (Aldrich). All organic chemicals used are analytical reagent grade (except 1,1,1-Trichloroethane at GPR grade) and used as received.

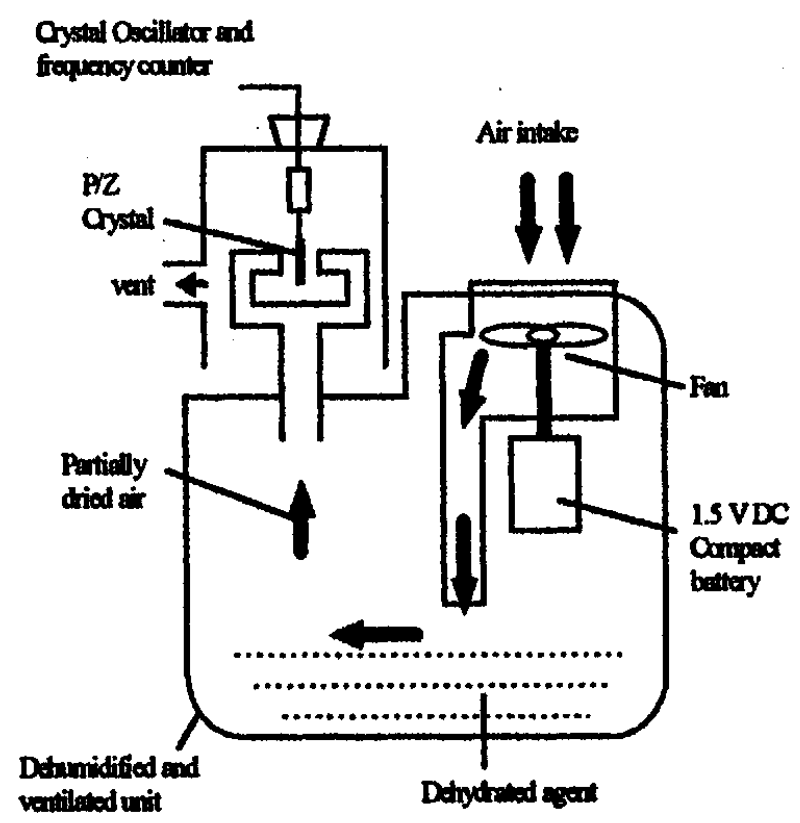

Fig.1 Organic Vapour Monitor Using Piezoelectric Crystal detection

\section{Procedure}

Coating materials were dissolved in suitable solvent and the solution was applied onto the entire surface of the electrode on both sides with a microsyringe. The crystal was then placed in an oven at about $50^{\circ} \mathrm{C}$ for several hours to evaporate the solvent and leave behind a uniform and thin film on the substrate. For studying the response factor, continuous sample gas was generated by a diffusion tube placed inside an impinger $(500 \mathrm{ml})$ immersed in a $25^{\circ} \mathrm{C}$ water bath. The organic solvent reservoir in the tube was swept by nitrogen at $40 \%$ relative humidity and flowrate $260 \mathrm{ml} / \mathrm{min}$, that is equal to the flow rate at the exit of the unit (face velocity : $0.38 \mathrm{~m} / \mathrm{s} \&$ diameter : $3.8 \mathrm{~mm}$ ). The concentration of the vapour generated can be changed by using different diameter and length of a glass capillary inserted on the diffusion tube and the concentration can be calculated from the flowrate and the weight 
loss over the experimental period. After at least two hour stabilization, the vapour generated was introduced to the organic monitor. The frequency of the oscillation was taken directly from the digital display on the counter with one minute interval and the response was regarded as the difference in frequency between the baseline and the absorption of the analyte.

Table 1 The sensitivity of the piezoelectric sorption detector to various VOCs under the

following conditions - temperature : $22^{\circ} \mathrm{C}$, flow rate : $260 \mathrm{ml} / \mathrm{min}$, relative humidity : $40 \%$.

\begin{tabular}{|c|c|c|c|c|c|}
\hline \multirow[b]{2}{*}{ Coatings } & \multirow[b]{2}{*}{$\begin{array}{l}\text { Bleeding } \\
\text { rate } \\
\mathrm{Hz} / \mathrm{min}\end{array}$} & \multicolumn{3}{|c|}{ Sensitivity $\mathrm{Hz} / \mathrm{ppm} / \mathrm{ug}$} & \multirow{2}{*}{$\begin{array}{r}\times 10^{-4} \\
\text { Eth }\end{array}$} \\
\hline & & Tol & Ben & Chl & \\
\hline AG & 0.3 & 39.5 & 8.2 & 10.3 & 17.6 \\
\hline HVG & 0.1 & 45.3 & 12.7 & 15.7 & 20.3 \\
\hline Silicone 550 & 1.5 & 53.0 & 16.0 & 14.5 & 13.9 \\
\hline Squalane & 0.7 & 53.2 & 10.7 & 8.9 & 13.3 \\
\hline PEG 400 & 0.5 & 23.2 & 6.3 & 18.3 & 11.1 \\
\hline PEG 1000 & 0.3 & 10.5 & 4.7 & 6.1 & 2.7 \\
\hline $\begin{array}{l}\text { Dioctyl } \\
\text { Phthalate }\end{array}$ & $\begin{array}{l}0.7 \\
(<10 u g) \\
3.3 \\
(>20 u g)\end{array}$ & 12.5 & 9.3 & 34.2 & 32.5 \\
\hline $\begin{array}{l}\text { Carbowax } \\
20 \mathrm{M}\end{array}$ & 0.3 & 9.3 & 1.1 & 6.9 & 3.6 \\
\hline
\end{tabular}

Tol $=$ Toluene, Ben=Benzene, Chl=Chloroform, Eth $=1,1,1-$ Trichloroethane

\section{Results and Discussion}

\section{(1) The Selection of Coating Material}

The sensitivity of the coated $P / Z$ crystals after exposure to various organic vapours was obtained in a screening test with results listed in Table 1. Dioctyl Phthalate is found to be the most sensitive coating for halogenated compounds and both Silicone 550 and Squalane give high response to aromatic compounds. Because of the relatively longer response time and larger volume of the dryer to the detector cell, the drifting in the baseline frequency is very important as it can lower the response observed and shorten the detector lifetime. Dioctyl Phthalate gives unacceptable high bleeding rate and both Silicone 550 and Squalane give high bleeding rate. On the other hand, both AG and HVG show acceptable sensitivity and high stability. Thus, AG and HVG are selected for detailed investigation.

Fig 2 The effect of the amount of coating on the response of 1,1,1-Trichloroethane under the following conditions - temperature : $22^{\circ} \mathrm{C}$, flow rate : $260 \mathrm{ml} / \mathrm{min}$, relative humidity : $40 \%$

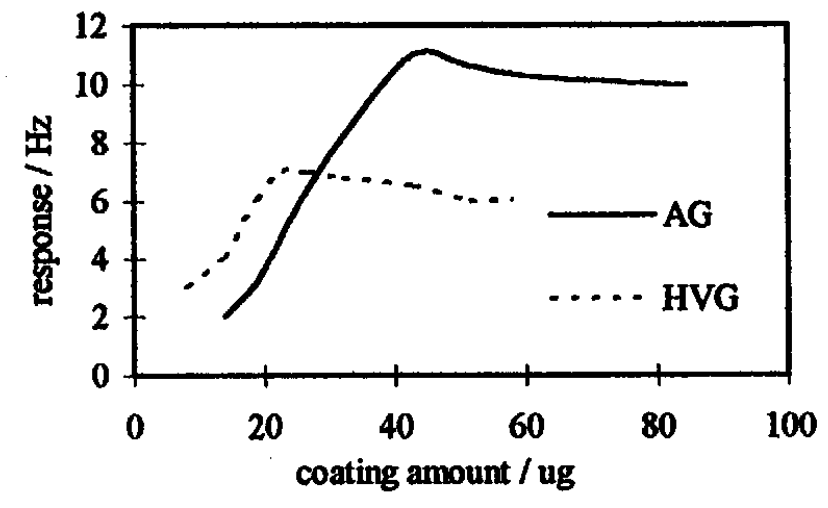

The effect of the coating amount of AG and HVG on the detection of $150 \mathrm{ppm} \mathrm{1,1,1-Trichloroethane}$ was shown in Fig.2. The use of coating weights amounting to a $20 \mathrm{kHz}$ (about $42 \mathrm{ug}$ ) and $11 \mathrm{kHz}$ (about 23ug) change in the crystal frequency was found to give the optimum results. Too high a coating mass would give a lower response. This may due to uneven coating for thick film that leads to poor adhesion of the coating on the electrode. 


\section{(2) The Response of the P/Z Sorption Detector with the Incorporation of the Dryer}

The response time of the organic vapour monitor towards 1,1,1-Trichloroethane was found to be short within minute and increased with the organic vapour concentration from about $300 \mathrm{ppm}$ to $780 \mathrm{ppm}$. In general, higher response was observed in higher concentration. The response factor of the coated crystals to four organic vapours were given in Table 2. The detector was found to be sensitive for the analysis of 1,1,1-Trichloroethane and Toluene as it gives response below their TLV values. Both AG and HVG give similar linear working ranges but AG gives a lower detection limit and a higher response at the same concentration. From Table 2, AG gives a better response factor than HVG except Toluene. The reproducibility of AG is not as good as HVG because a higher amount of the coating would lead to uneven film formation at the substrate. In general, AG, a well-known good coating for hydrocarbon, is the best material for the detector to be developed. However, HVG is a potential candidate as coating to detect total hydrocarbon.

Table 2 The response factor (RF) and linear working ranges under the following conditions -

temperature : $22^{\circ} \mathrm{C}$, face velocity : $0.38 \mathrm{~m} / \mathrm{s}$, relative humidity : $40 \%$

\begin{tabular}{|c|c|c|c|c|}
\hline & Tol & Ben & Chl & Eth \\
\hline \multicolumn{5}{|l|}{$\overline{\mathbf{A G}}$} \\
\hline lower (ppm) & 88.8 & 202 & 1440 & 306 \\
\hline upper (ppm) & 624 & 1080 & 1880 & 775 \\
\hline $\mathrm{RF}(\mathrm{ppm} / \mathrm{Hz})$ & 58.8 & 102 & 90.9 & 54.9 \\
\hline RSD \% & 29.5 & 47.1 & 22.2 & 24.0 \\
\hline \multicolumn{5}{|l|}{ HVG } \\
\hline lower (ppm) & 144 & 357 & 1400 & 351 \\
\hline upper (ppm) & 682 & 1080 & 2230 & 770 \\
\hline RF (ppm/tzz) & 43.1 & 147 & 141 & 78.2 \\
\hline RSD \% & 22.2 & 35.4 & 25.0 & 20.0 \\
\hline
\end{tabular}

\section{(3) The Applicability of the P/Z Sorption Detector}

Unknown concentration of Toluene was generated and sampled by the organic monitor. To ascertain the reliability of the monitor developed, parallel method comparison was carried out using the established GC-FID method as the reference method. A linear line was obtained from 0 to $800 \mathrm{ppm}$ Toluene with a product-moment correlation coefficient of the regression line equal to 0.9913 and the slope close to 1 with zero intercepts. Thus, same results were obtained over the concentration range studied.

In summary, the organic vapour monitor developed using piezoelectric crystal detection after a suitable dryer was installed to remove moisture interference is shown to provide a sensitive, lightweighed, cheap and portable analyser suitable for the monitoring of trace organic vapours in workplace air and indoor environment.

\section{Acknowledgments}

The authors would like to acknowledge the financial support from the Research Grants Council and the Hong Kong University Committee on Research and Conference Grants on the above project.

\section{References}

(1) I. Johansson, Atmos. Emviron., 12, 1371(1978).

(2) A.I.Clar, A.E.Mcintyre, J.N.Lester and R.Perry, Int.J., Environ. Anal. Chem., 17, 315 (1984).

(3) W.H. King, Jr. Emviron. Sci. Technol., 1970, 4, $1136(1970)$.

(4) W.H. King,, Jr. Anal. Chem., 36, 1735 (1964).

(5) T.E. Edmonds and T.S. West, Anal. Chim. Acta, 117,147(1980).

(6) J. Hlavay and G.G., Guilbault, G.G. Anal. Chem., 1978, 50,965

(7) Y.S. Fung, Z.C. Wu, Analyst, 1996,121,1955 